\title{
RISCO PARA PATERNIDADE OU MATERNIDADE PREJUDICADA EM FAMÍLIAS EM SITUAÇÃO DE RISCO DA REGIÃO LESTE DE GOIÂNIA.
}

\author{
RISK FOR PATERNITY OR DAMAGING MATERNITY" IN RISK SITUATION FAMILIES OF THE \\ EASTERN REGION IN GOIANIA.

\section{RIESGO PARA PATERNIDAD O MATERNIDAD PERJUDICADA" EN FAMILIAS EN SITUACIÓN DE RIESGO DE LA REGIÓN ESTE DE GOIÂNIA.}

\section{Viviane Meirelles de Oliveira ${ }^{1}$, Maria Márcia Bachion ${ }^{2}$}

RESUMO: Famílias em situação de risco social enfrentam múltiplos problemas que podem levar à alterações de saúde. Objetivamos identificar a ocorrência do D.E. "Risco para paternidade ou maternidade prejudicada" em famílias em situação de risco cadastradas por uma equipe do Programa de Saúde da Família de Goiânia. Trata-se de pesquisa descritiva realizada nos meses de abril a junho de 2004, mediante entrevista e observação direta de 30 famílias em situação de risco, selecionadas por sorteio entre as 106 famílias cadastradas pela equipe local. Apresentaram o diagnóstico em estudo $86,66 \%$ da amostra. Formam identificados nestas famílias de 05 a 39 fatores de risco, sendo a média de 18,23. Os fatores de risco identificados com freqüência maior ou igual a $50 \%$ foram: Classe socioeconômica baixa; Dificuldades financeiras; Falta de recursos; Pobreza; Ambiente doméstico pobre; Gravidez não-planejada ou não-desejada; Criança não-desejada ou nãoplanejada; Falta de uma rede social de apoio; Isolamento social; Baixo nível ou desenvolvimento educacional; Falta de acesso a recursos; Falta de transporte; Desemprego; Fracas habilidades para resolução de problemas; e Trabalho de parto e ou partos difíceis. Estes resultados nos permitem concluir que o risco para paternidade/ maternidade prejudicada apresentou-se com alta freqüência entre as famílias participantes, o que aponta para a necessidade dos enfermeiros se instrumentalizarem para prestar atendimento adequado a esta população, uma vez que a formação dos profissionais carece desta abordagem.

PALAVRAS CHAVE: Grupos de Risco; Diagnóstico de Enfermagem; Enfermagem Obstétrica

ABSTRACT: Families in a social risk situation face several problems that may lead to health changes. We aim to identify the occurrence of "Risk for paternity or damaging maternity" in risk situation families registered by a team of the "Goiânia Family Health Program". It is a descriptive research achieved from April to June of 2004, through interview and direct observation of 30 families in a risk situation, selected by a draw among the 106 families registered by the local team. About $86,6 \%$ of the sample presented the studied diagnosis. They were identified in these families 5 to 39 risk factors, reaching the average of 18,23 . The risk factors identified with higher or equal frequency than $50 \%$ were: low socioeconomic class; in financial troubles; resources lack; poverty; poor domestic environment; not planned or not wished pregnancy and children; support social net lack; social isolation; low level or educational development; access lack to resources; transport lack; unemployment; abilities weak to solve problems; and labor or difficult birth. These results allow us to conclude the risk for paternity or damaging maternity presented high often among the participant families, showing the nurses necessity of being prepared to attend appropriately the population, since these professional people are deprived of these qualities.

KEYWORDS: Risk Groups; Nursing Diagnosis; Obstetrical Nursing.

RESUMEN: Familias en situación de riesgo social enfrentan múltiples problemas que pueden llevar a alteraciones de salud. Objetábamos identificar la ocurrencia de "Riesgo para paternidad o maternidad perjudicada" en familias en situación de riesgo dadas por un equipo del Programa de Salud de la Familia de Goiânia. se Trata de búsqueda descriptiva realizada los meses de abril a junio de 2004, mediante entrevista y observación directa de 30 familias en situación de riesgo, seleccionadas por sorteo entre las 106 familias dadas de alta por el equipo local. Hubieron presentado el diagnóstico en estudio un $86,66 \%$ de la muestra. Forman identificados en estas familias de 05 a 39 factores de riesgo siendo la media

1 Enfermeira Especialista em Saúde da Família. Secretaria Municipal de Saúde de Goiânia. Rua C-243 Qda545 It19 n0121 Jardim América. Goiânia - Goiás. CEP: 74290-180vivimeirelles@yahoo.com.br

2 Enfermeira, Professora Doutora da Faculdade de Enfermagem da Universidade Federal de Goiás. Rua R-1 no 72 apto 702 Ed. Serra de Caldas, Setor Oeste.Goiânia. Goiás. CEP 74125 020. mbachion@fen.ufg.br 
de 18,23. Los factores de riesgo identificados a menudo mayor o igual la un $50 \%$ fueron: Clase socioeconómica baja; Dificultades financieras; Falta de recursos; Pobreza; Ambiente doméstico pobre; Embarazo no-planeada o no-deseada; Niño nodeseada o no-planeada Falta de una red social de apoyo; Aislamiento social; Bajo nivel o desarrollo educativo; Falta de acceso a recursos; Falta de transporte Desempleo; Débiles habilidades para resolución de problemas; y Trabajo de parto y o partos difíciles. Estos resultados en los permiten concluir que

\section{INTRODUÇÃO}

A estratégia do Programa de Saúde da Família propõe uma nova dinâmica para a estruturação dos serviços de saúde, bem como para a sua relação com a comunidade e entre os diversos níveis de complexidade assistencial. Assume o compromisso de prestar assistência universal, integral, equânime, contínua e, acima de tudo, resolutiva à população, na unidade de saúde e no domicílio, sempre de acordo com suas reais necessidades, identificando os fatores de risco aos quais ela está exposta, e neles intervindo de forma apropriada. Propõe-se ainda a humanizar as práticas de saúde, buscando a satisfação do usuário através do estreito relacionamento dos profissionais com a comunidade (SOUZA, 1999).

A definição de família é bastante diversificada e remete à diversas áreas de estudo, tais como a biologia, sociologia, antropologia, psicologia, direito, religião, entre outras (ANGELO \& BOUSSO, 2001).

Uma das abordagens atuais reconhece a família como unidade social formada por pessoas que têm laços de afinidade e consangüinidade, com quatro funções fundamentais: a social, a econômica, a reprodutiva e a educacional. É uma instituição social básica que aparece sob as formas mais diversas em todas as sociedades humanas. Descartadas as diferenças sociais e culturais, dá-se o nome de família a um grupo caracterizado pela residência em comum e pelo convívio de pais e filhos, isolados ou não dos demais parentes (SILVA et al, 1996).

O enfermeiro deve ser competente em acessar e intervir junto às famílias num relacionamento cooperativo - profissional/ família, tendo como base uma fundamentação teórica. Deve aliar os conhecimentos científico e tecnológico às habilidades de observação, comunicação e intuição.

Para comunicar as condições que requerem intervenções de enfermagem a nossa profissão desenvolveu ao longo de sua história várias taxonomias de diagnósticos de enfermagem. Na atualidade, uma das mais utilizadas é a Taxonomia da North American Nursing Diagnosis Association (NANDA, 2002).

Esta associação de cunho internacional adota como definição para diagnóstico de enfermagem "o el riesgo para paternidad/ maternidad perjudicada se presentó con alta frecuencia entre las familias participantes, el que apunta para la necesidad de los enfermeros se prepararem para prestar atención adecuada la esta población, una vez que la formación de los profesionales carece de este abordaje.

PALABRAS CLAVE: Grupos Vulnerables; Diagnóstico de Enfermería; Enfermería Obstétrica.

julgamento clínico das respostas do indivíduo, da família ou da comunidade aos problemas de saúde/processos de vida, reais ou potenciais" (CARPENITO, 1999, p. 27).

Mediante identificação do diagnóstico de enfermagem o enfermeiro toma decisões quanto aos resultados esperados por parte do cliente e às intervenções necessárias para ajudar a obter tais resultados (NANDA, 2002). Durante a nossa prática profissional no Programa de Saúde da Família, é comum vermos famílias que se encontram em condições de vida bastante especiais, e que exigem de nossa parte uma atuação diferenciada das demais famílias que acompanhamos. Trata-se de famílias consideradas em situação de risco.

A situação de risco pessoal e social de uma família é entendida como a situação vivida pela família em desvantagem, que lhe determina características gerais de múltiplos problemas (MARTIN \& ANGELO, 1998)

O perfil destas famílias é descrito como famílias chefiadas por mulheres; famílias com pessoas desempregadas; com maior número de filhos no período de adolescência; com falta de dinheiro (pobreza) e pouca opção de lazer (ANGELO \& BOUSSO, 2001). Somam-se a estes, educação limitada, o que as incapacita de funcionar adequadamente na sociedade mais ampla; estrutura e papéis familiares caracterizados pela composição da família por mulher, filhos e avós idosos; processos de comunicação familiar e socialização das crianças, que são peculiares e determinantes do risco tanto pessoal como social (MARTIN \& ANGELO, 1998).

Embora estes fatores sejam responsáveis pelo desencadeamento de crises no ciclo de vida dessas famílias, não obrigatoriamente desencadearão problemas, uma vez que a família é capaz de encontrar alternativas possíveis para enfrentar os diversos fatores estressantes considerados por ela (ANGELO \& BOUSSO, 2001).

Em uma família saudável, é presente a ajuda mútua, e para CIAMPONE et al (1999), vários fatores podem comprometer esse processo, tais como o desemprego, a miséria, falta de moradia, educação inacessível, desinformação, afastamento da mãe por longo tempo de seu filho, entre outros, dos quais, 
constituem riscos que podem levar a um "desvio da saúde familiar".

Os indicadores de risco que atualmente utilizamos na prática de enfermagem, na saúde da família englobam, além da falta de recursos financeiros que ocasiona privações de necessidades básicas como alimentação, vestuário, acesso a medicamentos, história ou evento de uma ou mais destas condições:

- Violência/maus tratos intra-familiar;

- Abuso de drogas ilícitas, ou alcoolismo;

- Mulheres adolescentes com número de filhos maior ou igual a dois;

- Crianças que se encontram em baixo peso;

- Crianças que se apresentam como cuidadores de outras crianças.

Falar em famílias em situação de risco nos remete a um fenômeno de natureza complexa no campo de atuação multidisciplinar. De nossa parte, enquanto enfermeiros, quando nos deparamos com esta situação, enfocamos condições que requerem intervenções de enfermagem.

Há escassez no número de publicações sobre diagnósticos de enfermagem em famílias, e em especial, em famílias em situação de risco. Assim, fazem-se necessários mais estudos nesta área.

Na área de abrangência do Programa de Saúde da Família do Recanto das Minas Gerais, equipe 02, na região leste de Goiânia, existem aproximadamente 1080 famílias cadastradas. Considerando os critérios descritos para caracterização de famílias de risco, podemos dizem que nesta área existem 106 famílias nestas condições. Ao convivermos com esta população no nosso cotidiano de trabalho deparamonos muitas vezes com o D.E. "Risco para paternidade ou maternidade prejudicada", contudo, não temos ainda investigado a casuística desta ocorrência em nossa área de atendimento, bem como seus determinantes e expressões, de modo sistematizado.

O "Risco para paternidade ou maternidade prejudicada" é definido como "risco de incapacidade do cuidador primário de criar, manter ou reaver um ambiente que promova o ótimo crescimento e desenvolvimento da criança" (NANDA, 2002, p.173).

Esta situação se apresenta como uma grande possibilidade na vigência de circunstâncias sociais (pobreza, falta de rede social de apoio, falta de coesão da família, conflito matrimonial, tensão/ sobrecarga de papel, pais solteiros, incapacidade de colocar as necessidades da criança à frente das suas próprias, entre outros), condições de falta de conhecimento (baixo nível ou desenvolvimento educacional, expectativas não realistas com relação à criança, falta de conhecimento sobre as habilidades necessárias aos pais falta de conhecimento sobre a manutenção da saúde da criança, falta de conhecimento a respeito do desenvolvimento da criança, entre outros), na vigência de determinadas situações fisiológicas (doença dos pais ou responsáveis) ou psicológicas (separação da criança, privação ou distúrbio do sono, história de abuso ou dependência de substância, entre outros) e condições ligadas à criança (doença da criança, nascimentos múltiplos, nascimento prematuro, entre outros). Estas condições podem se apresentar de forma isolada ou simultânea (NANDA, 2002).

Existe na família um compromisso e um vínculo entre os seus membros e as funções de cuidado da unidade consistem em proteção, alimentação e socialização (ANGELO \& BOUSSO, 2001). Quando os pais apresentam dificuldade para manter um adequado nível de crescimento e desenvolvimento dos seus filhos (maternidade/paternidade prejudicada) estes compromissos podem não ser cumpridos, além de não serem estabelecidos o vínculo afetivo e a adequada socialização. Isto pode comprometer não só as famílias atuais como a geração de famílias futuras.

Por outro lado, uma das expressões mais comuns da paternidade/maternidade prejudicada é a desnutrição infantil. Estudiosos como CIAMPONE et al (1999), reconhecem como fatores etiológicos da desnutrição o baixo nível sócio-econômico (pobreza/privação nutricional) e seus acompanhantes intrínsecos: as más condições ambientais (infecção, hospitalização), baixo nível educacional e cultural (criança negligenciada, não amamentada, com privação afetiva).

Estimar a magnitude e as formas de apresentação do risco para maternidade ou paternidade prejudicadas em famílias em situação de risco social poderá gerar informações que direcionem a tomada de decisões quanto às intervenções necessárias no contexto do Programa Saúde da Família da região de abrangência dos sujeitos.Além disso, possibilita situar este problema de saúde em relação a seus determinantes biopsicossociais, o que pode redirecionar tanto as práticas em saúde como o processo de formação profissional e de educação permanente, além de indicar possibilidades de pesquisas futuras.

\section{OBJETIVO}

Esta pesquisa tem como objetivo identificar a ocorrência de Risco para paternidade ou maternidade prejudicada (NANDA, 2002) em famílias em situação de risco, no Programa de Saúde da Família do Recanto das Minas Gerais, equipe 02, na Região Leste de Goiânia.

\section{MÉTODO}

Trata-se de pesquisa descritiva, realizada no período de abril a junho de 2004.

O projeto de pesquisa foi encaminhado ao Conselho Diretor da FEN/UFG, Secretaria Municipal de Saúde e Comitê de Ética em Pesquisa da UFG para análise, obtendo parecer favorável à sua realização em todas as instâncias.

Fizeram parte do estudo 30 famílias cadastradas na equipe 02 do Programa de Saúde da 
Família da região leste de Goiânia, e que se encontram em situação de risco, isto é apresentarem um, ou mais, dos seguintes critérios de inclusão: história de violência/maus tratos intrafamiliar; recursos financeiros escassos levando a privações de necessidades básicas como alimentos, vestuário e medicações;número de filhos de mulheres adolescentes maior ou igual a dois; crianças que se encontram em baixo peso; crianças que se apresentam como cuidadores de outras crianças; abuso de drogas ilícitas, ou alcoolismo.

Estes critérios foram selecionados por consistirem indicadores usuais no nosso trabalho no Programa Saúde da Família, além de constituírem em características dessas famílias, como mostra a literatura (MARTIN \& ÂNGELO, 1998; ÂNGELO \& BOUSSO, 2001).

Como critérios de exclusão elegemos não possuir filhos ou crianças sob seu cuidados.

Acessando o cadastro das 106 famílias consideradas pela equipe de saúde local como sendo de risco, foram excluídas 09 famílias que não possuíam filhos sob seus cuidados e foram confirmados os critérios de inclusão em 93 famílias, das quais sorteamos aleatoriamente 30 delas.

Após a seleção das famílias iniciou-se 0 processo de obtenção do consentimento dos seus membros para participarem da pesquisa, de modo voluntário, sendo garantido o direito de recusa ou retirada de consentimento para participar, sem qualquer prejuízo do atendimento à saúde oferecida pela Equipe de Saúde da Família local. Foi garantido anonimato dos participantes e os dados foram considerados privilegiados.

A obtenção dos dados foi realizada mediante a entrevista e observação direta do comportamento das pessoas, no domicílio, através de checagem em instrumento de coleta de dados. Trata-se de um roteiro com duas colunas. Na coluna da esquerda constam fatores de risco (fatores que aumentam a vulnerabilidade) e um conjunto de questões/ tópicos de observações que se referem a cada fator de risco pesquisado. $\mathrm{Na}$ coluna da direita o espaço é reservado para o pesquisador afirmar ou não a presença do fator de risco avaliado. Na taxonomia da NANDA, 2002, estão previstos 63 fatores de risco, agrupados em fatores sociais (30), de conhecimento (10), fisiológicos e psicológicos (11) e da criança (12). Examinados os conceitos de cada um destes fatores, procedemos ao agrupamento daqueles considerados como sinônimos (pobreza, falta de recursos, dificuldades financeiras, classe sócio-econômica baixa) e aqueles considerados próximos (conflito matrimonial, diminuição da satisfação, agrupados como problemas conjugais). Separamos aqueles que, apesar de condições próximas representam eventos distintos (pai não envolvido; filho não envolvido; desemprego; problemas no trabalho). Depois destes ajustes resultaram 28 fatores de risco sociais, 11 fatores fisiológicos ou psicológicos, 10 fatores de risco ligados ao conhecimento, 12 fatores ligados à criança, totalizando 61 fatores de risco pesquisados.

$O$ instrumento foi aplicado em três famílias em situação de risco, visando detectar as reações dos componentes destas diante da entrevista, bem como para promover maior domínio da condução do processo de interação e manejo do instrumento de coleta de dados. Devido à natureza do estudo, optouse pela realização da coleta de dados sempre pelo mesmo pesquisador.

Os dados foram analisados utilizando procedimentos de estatística descritiva, evidenciando a freqüência do D.E. na amostra, freqüência, média e moda dos fatores de risco.

\section{RESULTADOS E DISCUSSÕES}

Embora sejam previstos 6 estágios de desenvolvimento de famílias (WRIGHT \& LEAHEY, 2002), na atualidade é comum a interposição de estágios.

Das 30 famílias estudadas, 12 possuíam configuração do estágio 3 de desenvolvimento (famílias com filhos pequenos) e uma apresentava-se no estágio 4 (famílias com filhos adolescentes). As demais 17 famílias apresentavam estados híbridos de desenvolvimento, sendo que 6 destas famílias convivem simultaneamente com o estágio 3 e estágio 6 (famílias em final de vida). Cinco famílias apresentam concomitante ao estágio 3 características do estágio 5 (encaminhamento dos filhos e saída de casa). Seis famílias apresentam-se simultaneamente no estágio 3 e 4 (famílias com filhos adolescentes).

Ao longo do tempo, a estrutura familiar vem se alterando, nas diversas partes do mundo, dando origem à novas configurações familiares, para atender às suas necessidades face às condições sócioeconômicas vigentes.

Quanto à estrutura, a interposição também ocorreu. Podemos classificar 23 famílias como nucleares (casal e prole biológica ou consangüínea), sendo que destas, 2 são de segundas núpcias, em que os filhos do primeiro casamento não fazem parte do núcleo ora constituído. Outras cinco famílias são concomitantemente nucleares e adotivas (a prole tem relação de consangüinidade com um ou ambos genitores). Esta situação surge quando o casal ora constituído convive no mesmo domicílio com filhos biológicos de ambos e de apenas um dos progenitores (os filhos do primeiro casamento coabitam com os da segunda união). Temos ainda nove famílias que podem ser classificadas simultaneamente como nucleares e extensas (parentes de primeiro e sendo graus, além dos filhos, coabitam com os progenitores da família nuclear). Entre estas, cinco são famílias nucleares de um só genitor. Outras quatro famílias são nucleares de um só genitor. Quanto às duas famílias binucleares (convivência harmoniosa entre os cônjuges de primeira e segunda núpcias, fazendo com 
a prole coabite com ambas), uma delas é adotiva e a outra é de um só genitor.

Percebe-se assim que as classificações tanto para os estágios de desenvolvimento quanto de estrutura familiar não conseguem descrever adequadamente as novas configurações atualmente encontradas.

Com relação à idade dos progenitores, houve uma variação de 17 a 68 anos e para os filhos 4 dias a 23 anos. O número de moradores no domicílio variou de 3 a 11 pessoas, sendo a média igual a 5,33.

Entre estas 30 famílias participantes, identificamos que $26(86,66 \%)$ que apresentam Risco para Paternidade ou Maternidade prejudicada. Nas quatro famílias $(13,33 \%)$ restantes, foi observada a presença de Paternidade ou Maternidade Prejudicada já instalada.

Foi identificado de 05 a 39 fatores, sendo a média de 19,23 fatores, a moda igual a 13 e 14, o primeiro quartil igual a 13 fatores de risco na família, a mediana igual a 18 e o terceiro quartil igual a 25 fatores de risco.

Como pode ser visto na tabela 1 , a maioria das famílias convivem com 06 a 30 fatores de risco, tendo que enfrentá-los e superá-los. Chama a atenção a multiplicidade de fatores de risco, que pode chegar a uma condição extremamente adversa para a construção da maternidade/ paternidade, especialmente em duas famílias da amostra.

Tabela 1 - Distribuição do número de fatores de risco do D.E. "Risco para Paternidade ou Maternidade prejudicada", em 26 famílias em situação de risco. Programa de Saúde da Família do Recanto das Minas Gerais, equipe 02, Região Leste de Goiânia. 2004.

\begin{tabular}{ccc}
\hline $\mathrm{N}^{\circ}$ de Fatores de & $\mathrm{N}^{\circ}$ de Famílias & $\%$ \\
Risco & & 3,84 \\
\hline $1-5$ & 01 & 11,53 \\
$6-10$ & 03 & 26,92 \\
$11-15$ & 07 & 15,38 \\
$16-20$ & 04 & 15,38 \\
$21-25$ & 04 & 19,23 \\
$26-30$ & 05 & 3,84 \\
$31-35$ & 01 & 3,84 \\
$36-39$ & 01 & \\
\hline
\end{tabular}

Segundo CIAMPONE et al (1999), um ambiente de acolhimento e afeto é necessário para o crescimento e desenvolvimento da criança, objetivando a satisfação das suas necessidades básicas de cuidado, aprendizagem, carinho e alimentação, sendo que na ausência destas satisfações, poderemos encontrar risco para crescimento desproporcional. Porém, acrescentam as autoras, que os ambientes conflitantes e instáveis podem prejudicar a saúde da criança, lembrando que as suas interações físicas, emocionais, psíquicas e sociais, acontecem quase que exclusivamente, nos primeiros anos de vida, na família.

Contudo, esta adversidade nem sempre afeta a Paternidade ou Maternidade, com evidencia o estudo de VASCONCELOS, 2001, em que se percebe o vínculo afetivo, solidariedade e construção conjunta de projetos de melhoria em famílias em situação de risco social.

Para melhor visualização dos fatores de risco apresentados por estas famílias, os mesmos foram agrupados em "sociais" (tabela 2), "fisiológicos e psicológicos" (tabela 3), "de conhecimento" (tabela 4), e "do bebê ou da criança" (tabela 5).

Quanto aos fatores sociais (tabela 1), a Classe socioeconômica baixa/ dificuldades financeiras/ falta de recursos/ pobreza $(100,00 \%)$ constitui a maior ocorrência entre as famílias do bairro em questão. Esta condição foi considerada na presença de vida simples, regrada devido aos recursos financeiros escassos, havendo privações de lazer, de atividades sociais e em $65,38 \%$, privações de gêneros de primeira necessidade, incluindo alimentos e roupas. É característica ainda nessas famílias a dificuldade para honrar compromissos financeiros como aluguel, contas de água, energia elétrica, telefone, além da dificuldade de suprir suas necessidades de mobiliário para a casa, de acesso à domicílio com área física compatível com o número de moradores. Destas famílias $57,69 \%$ possuía pelo menos um membro empregado, o que nos remete ao fato de que, a renda salarial obtida não é suficiente para as suas necessidades básicas.

A escassez de recursos financeiros apresentouse mesmo em famílias nas quais detectamos que as mesmas possuíam carro (04 casos) e motocicleta (dois casos), todos em precárias condições devido ao tempo de fabricação, possuindo assim baixo valor venal. Bens como geladeira, fogão a gás e televisão eram todos de linha popular; os membros da família estavam empregados ou não.

O ambiente doméstico pobre assume características precárias, sendo as casas muito simples, de poucos cômodos, na grande maioria inacabadas, só no contra-piso e sem reboco, diante disto, úmidas, com limitações para uma melhor higienização do lar. De tais famílias, 07 delas (26,92\%) residem em lote com pelo menos 02 casas, sendo que 
$04(15,38 \%)$ dividem o lote com mais de 03 famílias. Em relação ao saneamento básico, todas utilizam água proveniente do sistema de tratamento de água, e os dejetos são canalizados para fossa. Trata-se de famílias que fazem refeições em número, quantidade (porções) e qualidade insuficiente, que dividem camas, sofás, colchões ou chão para dormir, cujas roupas estão muito desgastadas.

Apesar de todas estas restrições, todas as casas possuem geladeira e fogão. Existe aparelho de som em algumas delas. Apenas 01 casa não possuía televisão. Verificamos que 01 família não possui cama para todos, porém contam com telefone e televisor de boa marca.

$\mathrm{Na}$ sociedade pós-moderna globalizada caracterizada pelo consumismo, os desejos são tomados como necessidades e estas, por sua vez, são desvalorizadas. Cumpre salientar ainda que não nos cabe julgar estas famílias e "enquadrá-las" em nossa lógica, mas é importante compreender seu universo cultural, crenças e valores.

O IBGE considera desempregado apenas aquele que além de ter buscado emprego ativamente no período de referência, não executou qualquer atividade laboral. Inativo seria aquele que não procurou emprego nesse período. Aquele que trabalhou por algumas horas, se considera como ocupado.
O DIEESE considera de forma diferente, tanto o desemprego aberto como o oculto pelo trabalho precário ou pelo desalento. Ambos são considerados para se chegar a taxa de desemprego total (CARVALHO \& ALMEIDA, 2003).

Nessa pesquisa adotamos a concepção de desemprego tanto em sua forma aberta como oculta, identificando este fenômeno em $50,00 \%$ (tabela 2) das famílias. Esta situação afeta um ou ambos progenitores que passam a executar alguma ocupação informal como venda de bordados e tapetes, lavação de roupas, venda de cosméticos, capina em lotes vagos, serventes de pedreiro e pinturas em casas, todos referidos como "bicos". Além disso, são mencionadas outras fontes de renda, como o auxíliodoença; renda-cidadã; gás do governo; pensão alimentícia (em 03 casos, provenientes da avó, que ajuda na despesa e cuida das crianças para a mãe trabalhar); pensão por morte ou invalidez; segurodesemprego; salário-escola.

Estas "estratégias de sobrevivência" ou "estratégias familiares", têm como elemento central o trabalho complementar do cônjuge e dos filhos para compensar os baixos rendimentos do principal provedor. Segundo CARVALHO \& ALMEIDA (2003), tal fato se dá de acordo com a disponibilidade dos diferentes membros da família para o ingresso no mercado quanto pelas possibilidades de sua absorção.

Tabela 2 - Distribuição dos fatores de risco sociais do D.E. "Risco para Paternidade ou Maternidade prejudicada", em 26 famílias em situação de risco. Programa de Saúde da Família do Recanto das Minas Gerais, equipe 02,

Região Leste de Goiânia. 2004.

\section{Fatores de Risco}

- Sociais

\begin{tabular}{lcc}
\hline Classe socioeconômica baixa/ Dificuldades financeiras/ Falta de recursos/ & 26 & 100,00 \\
Pobreza & & \\
Ambiente doméstico pobre & 24 & 92,30 \\
Gravidez não-planejada ou não-desejada & 20 & 76,92 \\
Falta de uma rede social de apoio & 16 & 61,53 \\
Isolamento social & 15 & 57,69 \\
Falta de acesso a recursos & 14 & 53,84 \\
Falta de transporte & 14 & 53,84 \\
Desemprego & 13 & 50,00 \\
Fracas habilidades para resolução de problemas & 13 & 50,00 \\
Pai não-envolvido & 12 & 46,15 \\
Problemas conjugais & 12 & 46,15 \\
Mudança & 12 & 46,15 \\
Falta ou modelo pobre de papel de pai/mãe & 12 & 46,15 \\
Tensão/sobrecarga de papel & 11 & 42,30 \\
História de ser abusivo & 10 & 38,46 \\
Baixa auto-estima & 09 & 34,61 \\
Estresse & 09 & 34,61 \\
Falta de coesão da família & 09 & 34,61 \\
História de ter sofrido abuso & 08 & 30,76 \\
Falta de valor da paternidade/maternidade & 08 & 30,76 \\
Estratégias de enfrentamento mal-adaptadas & 08 & 30,76 \\
Pais solteiros & 07 & 26,92 \\
Mudança na unidade familiar & 06 & 23,07
\end{tabular}


Dificuldades legais

Arranjos inadequados para o cuidado da criança

Incapacidade de colocar as necessidades da criança à frente das suas próprias

Problemas no trabalho

Filho não-envolvido

$\begin{array}{ll}04 & 15,38 \\ 04 & 15,38 \\ 03 & 11,53 \\ 02 & 7,69 \\ 01 & 3,84\end{array}$

Mesmo entre as famílias que contam com emprego pode haver problemas no trabalho $(7,69 \%)$, como inadequadas formas de pagamento ("recebe aos poucos") ou demora (atraso) para o pagamento. Em configurações familiares, chefiadas pelas mulheres separadas e desempregadas, a mulher executa trabalhos informais para prover o sustento de seus filhos, ou então as fontes de manutenção da família incluem doações de conhecidos e de instituições religiosas.

Não foi possível levantar a média salarial das famílias entrevistadas, pela dificuldade em obtermos os valores reais ou estimados. Alguns informantes não sabiam referir, outros se negavam em relatar.

O uso de novas tecnologias e mão-de-obra mais qualificada tem gerado dificuldades e desigualdades no acesso às ofertas de trabalho, o que ocasiona um acentuado crescimento do desemprego e queda no rendimento médio dos que permanecem ocupados, levando a uma pobreza em massa, tendo como conseqüência o aumento das fileiras do mercado informal, representante de precárias condições e qualidades de ocupação. Por sua vez, a falta de rendimentos adequados traz forte impacto nas condições de vida da família, afetando negativamente sua capacidade de atender às necessidades básicas de seus membros e propiciar-lhes efetiva proteção social. (CARVALHO \& ALMEIDA, 2003).

A Falta de acesso a recursos $(53,84 \%)$ aparece como conseqüência de baixos rendimentos, aliado á precariedade das políticas sociais, diante das necessidades gigantescas da população, aliada à baixa oferta de atendimentos especializados de odontologia, fonoaudiologia nos serviços públicos de saúde, além de creche e auxílio à justiça. Assim, podese dizer que a rede social de apoio é precária.

A creche é apontada como necessária para que as mulheres possam trabalhar fora do domicílio. A falta de recursos para acesso a auxílio da justiça é mencionada por família composta por avó/ tia avó/ mãe com filhos menores de idade. Com separação do casal progenitor, há medo freqüente do pai das crianças, que não oferece suprimentos, e mesmo agressivo com as mesmas, ameaça retirar a guarda da mãe.

Encontramos uma alta freqüência de "Falta de uma rede social de apoio", 61,53\% (tabela 2). Nos afirma CARVALHO \& ALMEIDA (2003) e VASCONCELOS (2001), que mesmo com a implementação de políticas e programas sociais no país, elas continuam fragmentadas, pois se voltam para $\mathrm{o}$ atendimento individualizado das pessoas. Desconsidera-se o universo familiar e comunitário em que vivem; direitos de indivíduos isolados e direitos setorizados.

Dentre as famílias aqui inseridas, encontramos algumas que referem necessitar de passe-livre para os idosos, que embora presente na lei, ainda não foi instituído; auxílio-doença para uma criança hemofílica; auxílio/apoio para moradia própria, cesta básica. Outras onze famílias relataram sentirem falta de apoio, mas não sabiam referir em que tipo ou a quem recorrer.

O Isolamento social $(57,69 \%$ - tabela 2$)$, ocorre como resultado do perfil sócio-econômico precário. As famílias referem sentir falta de contato com outras pessoas, como em atividades comunitárias, confraternizações ou reuniões familiares, principalmente quando o núcleo familiar é extenso. Às vezes a instituição religiosa é o único cenário para atividade de integração social. As opções de lazer são escassas e às vezes não acessíveis para as crianças. Outra fonte de isolamento social para as famílias é a não aceitação de um dos cônjuges pela família extensa do outro. Assim as famílias permanecem isoladas.

A Falta de transporte $(53,84 \%$, tabela 2$)$, referese não só a ausência de veículos automotores próprios como a dificuldade/ impossibilidade de utilização de transporte coletivo, devido à falta de dinheiro. Este fato restringe o acesso a serviço de saúde, trabalho, creche ou escola.

O Conflito matrimonial $(46,16 \%)$ ocorre em 12 famílias, sendo devido a inúmeros fatores, tais como pai não envolvido (08 casos), brigas freqüentes, por dificuldades financeiras, envolvimento do marido em jogos de azar, disputa pela guarda das crianças, e em apenas 01 caso, por alcoolismo. São referidos "muitos motivos", entendido aqui como pequenos dissabores ou contrariedades que assume efeito cumulativo e são referidos pelas mulheres. No caso de 01 referência de filho não-envolvido, tratava-se de situação em que, com pais separados, a mãe constituiu nova união consensual, e refere que a criança estava rebelde, levando a conflitos com o novo parceiro.

Pai não envolvido (pai ou mãe) foi relatado em 12 casos $(46,15 \%)$. Esta condição referiu-se ao pai propriamente dito, relatado pelas mulheres (11 casos). A maioria deles não apresenta circunstância especialmente crítica para este não envolvimento, segundo as informantes. Contudo, em 02 casos, o pai não reside na companhia da mãe, sendo que 01 caso nunca houve convivência com a criança. Foi identificada uma mãe não-envolvida. Tratava-se de uma mulher com quadro de distúrbio psiquiátrico, "depressão", com alterações esquizofrênicas da linguagem, caracterizado por parafrasias (deformação 
de palavras), jargonofasia (fala incompreensível), para-respostas (sem ter a ver com a pergunta) e mussitação (murmúrio ininteligível).

Segundo CARVALHAES \& BENÍCIO (2002), a saúde mental materna pode elevar o risco para desnutrição. Afirmam que as precárias condições emocionais maternas podem levar a um padrão de cuidado infantil inadequado, aumentando o risco de doenças, e a manutenção desta, afetaria a mãe, contribuindo para mantê-la deprimida e impotente.

"Fracas habilidades para resolução de problemas" foi identificado em $50,00 \%$ dos casos. As famílias têm enfrentado problemas que atualmente, não estão conseguindo solucionar com êxito, além de não vislumbrar perspectivas de alcance de resultados de impacto duradouro. São situações de falta de comida; salário insuficiente; muitas contas a pagar; desemprego; alcoolismo; ausência do pai no lar; doenças na família; moradia inadequada e uso de drogas.

Para o fator de risco Mudança, buscamos detectar mudanças no âmbito de troca de moradias ou modificações gerais na vida dos membros da família, e, em Mudança na unidade familiar, focalizamos alterações na composição familiar, abordando se os acontecimentos Ihes trouxeram dificuldades. Encontramos o relato de Mudanças em 46,15\% e Mudança na família em $23,07 \%$. São pessoas sem moradia fixa que referem muitos transtornos familiares decorrentes da dificuldade de pagar o aluguel; de se encontrar uma casa com preço acessível e espaço suficiente para família; do incômodo de dividir o espaço com outros membros da família extensa, o que agrava quando se mora de favor. Entre as famílias que referiram mudanças que não seja relacionada ao endereço de residência, tivemos conflitos decorrentes de desemprego. Duas relataram desentendimento entre os filhos e doença no patriarca.

Quanto a mudanças na unidade familiar foram referidas gravidez e separação do casal.

Em "Falta de coesão da família" identificado em $34,61 \%$, buscamos levantar como ocorriam as interações entre os membros familiares, relacionado às discussões de problemas e soluções. Foi identificada a falta de diálogo entre o casal. As mulheres respondentes relataram "esposo muito fechado" ou "esposo não gosta de conversar sobre os problemas". Disseram dividir as questões emocionais com os pais, irmãos ou "apenas com Deus".

A "Falta ou modelo pobre de pai e mãe", presente em $46,15 \%$. Refere-se à situações relatadas pelas famílias de progenitores alcoólatras; muito autoritários; pobreza; ter sido adotada; não ter convivido com os pais, por morar fora de casa para ajudar no sustento; e o fato do pai ter mantido duas famílias ao mesmo tempo. Também foi referido "pais muito ásperos"; separação dos pais ainda na sua infância; ter sido criada pelos irmãos ou por mãe adotiva.
Perfazendo um total de 11 casos $(42,30 \%)$ para o fator de risco Tensão/ sobrecarga de papel, as informantes se referiram como as únicas responsáveis pela manutenção da casa; cuidados das crianças, algumas cuidam de outras crianças recebendo pagamento em troca; o fato de ter que se preocupar em "fazer bicos" para o sustento da família; residir no mesmo lote que os irmãos alcoólatras; as constantes brigas na família; e cuidar de familiar com doença crônica (doentes renais crônicos, hemofílico e idoso hipertenso).

Dentre as famílias que apresentaram História de ser abusivo (38,46\% - tabela 2$)$, cinco estão incluídas nas que referem tensão/ sobrecarga de papel, sendo que em duas famílias a fonte da agressividade é o pai (grosseria, estupidez) e em duas é a mãe (muito exigente com a organização da casa).

Sem o fator de risco associado, em 03 famílias encontramos mulheres que relatam que os esposos queixam que elas falam demais, e outras 02 , que apontam brigas constantes com esposo ou ameaça por parte do ex-marido.

Para "Baixa auto-estima" e "Estresse", presentes em 34, $61 \%$ das famílias entrevistadas, destas 09 mulheres que referiram a auto-estima diminuída, 05 delas também referiram viver um momento cheio de desmotivação, extremo cansaço, choro intenso por qualquer motivo, e ansiedade, configurando a situação de vivência de estresse. Relataram insatisfação pela falta de dinheiro e saúde das crianças precária; e "acha que está com depressão".

Em quatro famílias, a baixa auto-estima foi referida por quatro mulheres, pelo fato de quererem trabalhar; cursar curso superior; estar "cansada de problemas"; e "sofrimento por ter que viver sempre em depressão". Em uma destas famílias o homem referiu humilhação gerada pelo desemprego.

Quatro casos referidos de "Estresse", não fazem referências a causas específicas, porém há destaque para os sintomas choro intenso por qualquer motivo e esquecimento.

"História de ter sofrido abuso" (30,76\% - tabela 2) foi abordado do ponto de visto da vigência de traumas anteriores. Das famílias onde o fator de risco esteve presente, 05 mulheres se negaram em discorrer sobre o fato, ou apontaram que não conseguiriam. Para três respondentes, mulheres, as causas foram assédio sexual por parte do proprietário da casa que morava; exploração por parte da família adotiva; e estupro pelo ex-marido.

Destacamos que daquelas famílias que relataram "História de ter sofrido abuso", 03 delas também apresentaram "Falta de valor da paternidade/ maternidade", fator de risco presente em 08 famílias $(30,76 \%)$. Através do relato destas, percebemos o conflito da definição do papel da mãe, maioria das entrevistadas. Para os outros casos, as informantes nos relatam que os pais são indiferentes com seus 
filhos; alguns falam da preferência de um filho em detrimento aos outros; e abandono.

Em "Estratégia de enfrentamento maladaptadas" $(30,76 \%)$, abordamos a questão de como reagem diante da necessidade de ação imediata, sendo que 02 famílias referem estar difícil enfrentar os problemas, pois não conseguem soluções; 04 respondentes relatam não conseguirem ao menos pensar, em decorrência do nervosismo; 01 família relata que procura meios, sem conseguir encontrar uma saída, e 01 aponta estar confusa diante da situação que estão vivenciando no momento.

Para Pais solteiros, $26,92 \%$, temos 02 famílias onde só residem as mães e as crianças, decorrente de separação do casal; 03 em que as mães não moram com o pai das crianças, mas já coabitaram; e 02 famílias de pais que vivem com seus pais e filhos, os quais foram abandonados pela mãe.

Destacamos que em "Arranjos inadequados para o cuidado das crianças" $(15,38 \%)$, inclui condições em que as mães permanecem em casa, não exercendo atividade laboral nem dentro e nem fora do domicílo, porém, seus filhos se apresentam mal-cuidados e sujos. Inclui ainda circunstâncias em que as avós ou bisavó, com mais de 60 anos de idade são cuidadoras de mais de uma criança menor de 5 anos.

Quanto aos fatores fisiológicos e psicológicos (tabela 3) entre os fatores fisiológicos, consta na taxonomia da NANDA (2002), Doença física. Nesse item, buscamos identificar a presença de doença nos progenitores ou responsáveis pelas crianças e a descrição de como estavam sendo as estratégias de enfrentamento. Dos $38,46 \%$ de casos para os progenitores, nos foram referidos problemas na coluna; bronquite; diabetes; hipertensão arterial; insuficiência renal crônica; e em 01 família apenas, esposa poliqueixosa.

Ao assistir famílias deve-se ter em mente que a doença é uma experiência que envolve toda a família (ANGELO \& BOUSSO, 2001; CIAMPONE et al, 1999). A saúde de cada membro influencia a unidade familiar e também há influência da unidade familiar sobre a saúde de cada indivíduo na família, incorporando este conhecimento ao plano de cuidado.

Gravidez não-planejada nos foi referida em $76,92 \%$ dos casos (tabela 2), porém todas as mulheres afirmaram que a gravidez e a criança foram desejadas, mesmo não tendo sido planejada.

Estes achados indicam que o planejamento familiar ainda se constitui em desafio tanto para os profissionais de saúde como para a população em risco social. As estratégias utilizadas até agora aparentemente não têm produzido resultados satisfatórios. Por outro lado, a baixa escolaridade, os tabus na área da sexualidade no contexto familiar dificultam a adoção da prática de sexo seguro.

Das 20 famílias que apresentaram gravidez não planejada, em 10 a primeira gestação ocorreu quando as mulheres eram adolescentes.
A gravidez ocorrida na adolescência representa fator de risco tanto à saúde materna quanto fetal, à medida em nesta condição podemos encontrar uma baixa cobertura de pré-natal, maior incidência de toxemias, anemias, infecções urinárias, prematuridade, baixo peso ao nascer e desmame precoce, o que pode se configurar como risco para crescimento desproporcional (CIAMPONE et al, 1999), além de risco para maternidade/ paternidade prejudicada.

O Trabalho de parto e/ou parto difíceis, foi relatado em $50,00 \%$ dos casos (13 mulheres, das quais 03 foram primíparas na adolescência). Foram descritos "parto a ferro", "criança que nasceu pelo pé"; e hemorragia, levando a cesárea inesperada, casos de eclâmpsia; dor extrema; hemorragia pós-parto, referida em 02 famílias; "parto natural difícil porque a criança era muito grande"; e "parto complicado pois havia mecônio".

Falta de (ou muito tardia) assistência pré-natal foi identificada em $34,61 \%$ das famílias entrevistadas (tabela 3). Quatro mulheres, todas primigestas ainda adolescentes, referiram início aos 04 meses de gestação. Cinco mulheres relataram não ter realizado pré-natal em pelo menos uma gestação, sendo que 03 delas foram primigestas na adolescência.

A falta de adesão ao pré-natal na adolescência também foi identificada no estudo de CIAMPONE et al (1999). Trata-se de fenômenos com múltiplas causas.

$\mathrm{Na}$ ausência de assistência pré-natal, podem deixar de ser detectadas situações de risco à saúde materno-fetal e condições desfavoráveis ao estabelecimento de vínculo-mãe-filho e pai-filho bem como o aprendizado sobre os cuidados com o recémnascido, levando ao risco de paternidade/ maternidade prejudicada.

A depressão, apresentou-se como fator de risco presente em $42,30 \%$ das famílias entrevistadas (tabela 3) e nos foi referida como um conjunto de sinais e sintomas, decorrente de condições de vida que enfrentavam naquele momento, nas quais se deparavam com muitos conflitos familiares, dificuldades financeiras, ameaça de perda da tutela dos filhos, falta de moradia, desemprego, convívio conjugal insuportável. Com diagnóstico de depressão e tratamento medicamentoso e psicoterápico, encontramos o membro de uma família.

A História de abuso ou dependência de substância, encontrada em 42,30\% (tabela 3), referese ao uso de álcool, maconha, e tabaco. A informação foi obtida junto aos membros da família ou pela declaração do próprio usuário de drogas. Neste caso é comum se instalar ambiente completamente adverso ao vínculo afetivo e atenção às necessidades da prole, além de dificuldade para um padrão de comunicação eficaz.

Entre as mulheres, 02 desempregadas, 05 faziam uso abusivo do cigarro, e nenhuma alcoolista ou usuária de maconha. Entre os homens, 03 
desempregados, 08 deles fumantes, 05 alcoolistas e 01 usuário de maconha.

Na média de consumo destas substâncias, foi referido para o cigarro, "muitos por dia"; "10 a 15 por dia"; "01 carteira por dia" e "de 04 a 05 carteiras por dia para o casal", sendo o homem, usuário de droga. Para o álcool, as informantes, mulheres dos alcoolistas, relataram como "menos que antes"; "às vezes"; e "diariamente".

Tabela 3 - Distribuição dos fatores de risco fisiológicos e psicológicos do D.E. "Risco para Paternidade ou Maternidade prejudicada", em 26 famílias em situação de risco. Programa de Saúde da Família do Recanto das Minas Gerais, equipe 02, Região Leste de Goiânia. 2004.

\begin{tabular}{lcc}
\hline Fatores de Risco Fisiológicos & $\mathrm{n}$ & $\%$ \\
\hline Doenças nos pais ou responsáveis & 10 & 38,46 \\
\hline Fatores de Risco Psicológicos & & \\
\hline Trabalho de parto e/ou partos difíceis & 13 & 50,00 \\
Depressão & 11 & 42,30 \\
História de abuso ou dependência de substância & 11 & 42,30 \\
Falta de (ou muito tardia) assistência pré-natal & 09 & 34,61 \\
Pouca idade, especialmente adolescentes & 08 & 30,76 \\
Grande número de filhos ou partos com pequenos intervalos & 07 & 26,92 \\
Privação ou distúrbio do sono & 07 & 26,92 \\
Deficiência & 05 & 19,23 \\
História de doença mental & 02 & 7,69 \\
Separação do bebê/criança & 01 & 3,84 \\
\hline
\end{tabular}

A falta de emprego limita muitas vezes o homem para exercer o seu papel de provedor na família, levando-o a sentir-se fracassado ou ainda deprimido, podendo desencadear o alcoolismo ou abandono da família (CARVALHO \& ALMEIDA, 2003).

Entre estas famílias com História de abuso ou dependência de substância, cumpre acrescentar, que independente da substância utilizada, 04 delas, fazem parte daquelas elencadas dentro do fator de risco História de ser abusivo (38,46\% - tabela 2), onde as esposas se queixam do marido, todos desempregados. Em 02 famílias, com apenas as mulheres fazendo abuso de substância (cigarro) nos referiram que os demais membros da família queixam que ela "fala demais" ou reclamam que ela "exige as coisas muito certinhas".

O fator de risco Pouca idade (dos progenitores) especialmente adolescentes (tabela 3 ), foi identificado em $30,76 \%$ das famílias.

A gravidez na adolescência configura-se em situação de risco para paternidade ou maternidade prejudicada, porque nesta fase de desenvolvimento o indivíduo está vulnerável às mudanças biopsicossociais. Segundo GODINHO et al (2000), nesta fase existe falta de racionalização sobre as conseqüências futuras decorrentes do comportamento sexual, tendo como decorrência uma possível gravidez não planejada ou não desejada. Nesta situação ocorre o risco de não se estabelecer os vínculos parentais com o futuro filho. Estas autoras referem que gestantes adolescentes apresentam um certo distanciamento da realidade concreta do dia-a-dia, o que as isenta de se preocupar com o seu sustento e de seu filho. Tal fato é manifestado pelo desconhecimento da renda mensal familiar, e a ocorrência da gravidez por gostarem de criança e pelo desejo de ter um filho. Após o parto, muitas vezes questionam o significado da criança em sua vida e se deparam com a falta de condições financeiras para criá-la, pois muitas vezes lhe falta o apoio da família e/ou do parceiro, ocorrendo o rompimento da relação ainda durante a gravidez.

Grande número de filhos ou partos com pequenos intervalos $(26,92 \%$ - tabela 3$)$, foi identificado em mulheres com prole compreendida entre 02 a 09 crianças, sendo a maioria com 05 filhos, com intervalo máximo de 02 anos entre o nascimento deles.

"Privação ou distúrbio do sono", foi identificada em $26,92 \%$ das famílias, que corresponde a 06 casos. O relato é de que de não dormem bem por preocupações, em primeiro lugar, com as condições financeiras, seguido das dificuldades nos relacionamentos interpessoais na família.

Entre as famílias que indicaram "Deficiência" $(19,23 \%)$, compreendida como alterações dos órgãos dos sentidos e na movimentação por parte dos progenitores, foram referidas apenas alterações não limitantes, ou seja, aquelas que podem ser minimizadas com o uso de órteses, como óculos ou aparelho de audição. Quatro famílias apresentam um dos progenitores com queixa da diminuição da acuidade visual e um caso de perda da audição no ouvido esquerdo.

Os casos de "História de doença mental", 02 casos $(7,69 \%$ - tabela 3$)$ tratam-se famílias em que um dos membros apresenta diagnóstico médico de depressão e estão em tratamento. Em ambos os casos a doença mental apresenta-se na matriarca.

A separação do bebê/ criança $(3,84 \%)$ nos foi relatada como período em que a mãe ficou por 03 
meses sem contato com filho menor de 01 ano, retomando a convivência depois disso.

Acreditamos, que Baixo nível ou desenvolvimento educacional, encontrado em 57,69\% dos casos (tabela 4), está ligado a Classe socioeconômica baixa (tabela 2). Nestas famílias, a formação educacional dos progenitores está caracterizada pelo ensino fundamental incompleto; seguida do ensino médio (completo ou não) e analfabetismo em 05 progenitores, sendo que em 01 família esta condição era apresentada pelo casal.

Tabela 4 - Distribuição de fatores de risco de conhecimento do D.E. "Risco para Paternidade ou Maternidade prejudicada”, encontrados em 26 famílias em situação de risco. Programa de Saúde da Família do Recanto das Minas Gerais, equipe 02, Região Leste de Goiânia. 2004.

\begin{tabular}{lc}
\hline Fatores de Risco de conhecimento & $\mathbf{n}$ \\
\hline Baixo nível ou desenvolvimento educacional & 15 \\
Poucas habilidades de comunicação & 57,69 \\
Preferência por punições físicas & 19,23 \\
Falta de preparo cognitivo para a maternidade & 03 \\
/paternidade & 02 \\
Expectativas não realistas com relação à criança & 7,69 \\
Incapacidade de reconhecer e agir sobre os sinais emitidos pela criança & 01 \\
Falta de conhecimento sobre a manutenção da saúde da criança & 3,84 \\
Falta de conhecimento a respeito do desenvolvimento da criança & 3,84 \\
Falta de conhecimento sobre as habilidades necessárias aos pais & 01 \\
Funcionamento cognitivo limitado & 3,84 \\
\hline
\end{tabular}

Com base na interação interpessoal do momento da aplicação do instrumento, na possibilidade de retorno claro e objetivo às indagações, "Poucas habilidades de comunicação", $19,23 \%$, foi identificado em famílias com baixo nível educacional (até educação fundamental), mediante respostas fechadas e conclusivas, entre as quais estava uma família com membro (matriarca) com quadro depressivo. A falta de habilidades de comunicação pode interferir na formação do vínculo pais e filhos, bem como afetar o processo de socialização das crianças, que geralmente adotam $o$ modelo dos genitores.

Encontramos a preferência por punições físicas em 03 famílias $(11,53 \%)$. Destacamos em uma das famílias o casal está separado e a mãe refere que as crianças apresentam comportamento impulsivo e rebelde. Em outra situação, a mãe abandonou os filhos com o pai, que deixou a educação dos mesmos a cargo da avó paterna. Numa outra família em que coabitam onze pessoas, as cinco crianças não convivem ou não conhecem seus pais (homem).

$\mathrm{Na}$ "Falta de preparo cognitivo para a maternidade/ paternidade", nos informaram medo ou história de medo e dificuldades nos cuidados diários com a criança $(7,69 \%)$, tais como o banho do recémnascido. Em outra família foi percebido o medo de complicações do transplante renal na criança de 08 anos.

"Expectativas não realistas com relação à criança" (Tabela 4 - 3,84\%) teve como expressão nas famílias pesquisadas uma situação em que a cuidadora não tem expectativa nenhuma com relação às crianças. Em meio à angústia, diante da magnitude dos problemas, na ausência dos pais das crianças, e referindo que suas filhas, mães das crianças, "não pensam", a avó cuidadora, cita "só Deus pra dar jeito".

Em se tratando de "Incapacidade de reconhecer e agir sobre os sinais emitidos pela criança" $(3,84 \%)$ foi observado no lar em que a mãe é portadora de depressão e afirma não saber reconhecer quando seus filhos necessitam de alguma coisa, necessitando que o marido realize esta função

Em casos isolados, a Falta de conhecimento sobre a manutenção da saúde da criança e Falta de conhecimento a respeito do desenvolvimento da criança, ambos encontrados em 3,84\%, diz respeito à situação em que os entrevistados não souberam referir como evitar que as crianças adoeçam ou quais cuidados são executados pela família para manutenção da saúde, e referem que as crianças são muito doentes, com baixo peso (o que não é real) e presença de verminose. Para o segundo fator de risco, a cuidadora da criança, a mãe, acredita que o único parâmetro para se avaliar o desenvolvimento de uma criança é pelo apetite. Acrescentamos que trata-se de criança de baixo peso, com quadros de pneumonia recorrentes no primeiro ano de vida.

A situação econômica da família pode causar um impacto no cuidado da criança, e segundo CARVALHAES \& BENÍCIO (2002), este fato é mais freqüente entre as mães sem companheiro. As autoras realizaram estudos acerca da capacidade materna em cuidar dos seus filhos associada à desnutrição infantil, e afirmam que as habilidades maternas dependem de sua escolaridade e ambiente cultural, de seu próprio estado de saúde física e mental, e de sua autonomia e autoconfiança. Para elas, é preciso contar com a ajuda da família e da comunidade nos momentos dos diferentes tipos de crise vivenciados. 
Casos de Criança não-planejada ou não desejada foram referidos em $69,23 \%$ das famílias entrevistadas (tabela 5). Destacamos, que embora não planejadas, as crianças foram desejadas.

Em Condição deficiente ou retardo de desenvolvimento $(42,30 \%$ - tabela 5), levamos em consideração o fato das crianças apresentarem, ou já terem apresentado algum problema no desenvolvimento. Nos foram referidos hemofilia; intolerância à lactose; pneumonia, com internações freqüentes em criança menor de 01 ano; degeneração em membro superior ocasionada por fratura no parto, ainda sem intervenção cirúrgica; criança que só começou andar com 03 anos; criança que "passou da hora de nascer"; e baixo peso presente em crianças maiores de 02 anos.

Crianças que apresentam Temperamento difícil foram referidas em $38,46 \%$ das famílias entrevistadas (tabela 5). Dentre as crianças que as mães nos referiram, foram definidas como "cheias de vontade", não possuem limites e não respondem às ordens dos pais ou responsáveis.

Entre estas crianças, a Falta de benevolência para adequar-se (temperamento) às expectativas dos pais $(23,07 \%)$ nos foi referida em 05 casos, acrescentando-se àqueles comportamentos, o fato das crianças exigirem dos pais brinquedos ou objetos pessoais que não está acessível ao poder aquisitivo da família.

"Ser de sexo não-desejado" (tabela 5) encontrado em $30,76 \%$ dos casos, coincide, em 05 famílias com a referência de crianças com temperamento difícil, que não preencheram, em algum momento de suas vidas, aquilo que os pais desejavam. Para as outras 03 crianças, além do não atendimento à preferência dos pais quanto ao sexo, foram feitas referências acerca de condição deficiente ou retardo de desenvolvimento, como desnutrição e "dificuldade para andar".

Tabela 5 - Distribuição de fatores de risco do bebê ou da criança do D.E. "Risco para Paternidade ou Maternidade prejudicada" em 26 famílias em situação de risco. Programa de Saúde da Família do Recanto das Minas Gerais, equipe 02, Região Leste de Goiânia. 2004.

\begin{tabular}{lcc}
\hline Fatores de Risco do bebê ou da criança & $\mathbf{n}$ & $\mathbf{\%}$ \\
\hline Criança não-planejada ou não-desejada & 18 & 69,23 \\
Condição deficiente ou retardo de desenvolvimento & 11 & 42,30 \\
Temperamento difícil & 10 & 38,46 \\
Ser de sexo não-desejado & 08 & 30,76 \\
Separação prolongada dos pais & 08 & 30,76 \\
Transtorno de déficit de atenção/hiperatividade & 07 & 26,92 \\
Doença & 06 & 23,07 \\
Falta de benevolência para adequar-se (temperamento) às expectativas dos pais & 06 & 23,07 \\
Habilidades perceptivas alteradas & 04 & 15,38 \\
Separação da mãe/pai ao nascimento & 04 & 15,38 \\
Nascimento prematuro & 03 & 11,53 \\
Nascimentos múltiplos & 01 & 3,84 \\
\hline
\end{tabular}

"Separação prolongada dos pais" (30,76\%) ocorreu em famílias em que o pai das crianças ficou afastado por muito tempo delas, por motivo de separação do casal ou casos em que os pais não conhecem ou tiveram pouquíssimo contato com seus filhos ou ainda em situações em que as mães abandonaram seus filhos com o pai. Ressaltamos que das quatro famílias em que houve a "Separação da mãe/ pai ao nascimento" (15,38\%), três delas também apresentaram separação prolongada dos pais, sendo que uma delas refere-se à mãe e duas ao pai.

Consideramos importante comentar o fator de risco "Transtorno de déficit de atenção/ hiperatividade", detectado em 26,92\% das crianças (tabela 5), conforme o relato das famílias, sob o ponto de vista da sua apresentação concomitante nos casos de temperamento difícil e separação prolongada dos pais. Estas famílias caracterizaram o comportamento das crianças pela agitação psicomotora, dificuldade de concentração numa atividade, passando de uma atividade para outra muito rapidamente, não se satisfazendo com apenas uma atividade de cada vez. Houve referências de doenças nas crianças $(23,07 \%)$, tais como "fala enrolada"; verminose; hemofilia; pneumonia recorrente; insuficiência renal crônica, com transplante renal há menos de 06 meses; e "urina solta". As doenças nas crianças podem frustrar as expectativas dos pais.

Referente ao fator de risco "Habilidades perceptivas alteradas" $(15,38 \%)$ nas crianças, foi encontrado na faixa etária de 04 a 13 anos problemas na acuidade visual, como queixas de "dor nas vistas" ao assistir televisão e ardência durante a leitura.

"Nascimento prematuro" (11,53\%) ocorreu em três casos, sendo que em um deles a mãe não realizou o pré-natal e era fumante outra mãe apresentou "queda durante a gestação", e a outra teve parto gemelar.

Encontramos a presença de apenas 01 parto gemelar, caracterizando nascimentos múltiplos em 01 família da amostra (3,84\%, tabela 5$)$. O nascimento 
de uma criança demanda esforço adaptativo dos familiares, especialmente da mãe. No caso de nascimentos múltiplos pode haver sobrecarga do cuidador e alteração da maternidade ou da paternidade.

Os profissionais de saúde geralmente são despreparados para lidar com o contexto social familiar na sua interface com problemas de saúde concretos ou potenciais. É preciso perceber a influência de dimensões mais centrais sobre os problemas familiares, e atuar de forma sistemática e persistente, iniciando pelos problemas mais freqüentes, como a falta de emprego, a falta de renda, que impede acesso a alimentação, vestuário, moradia e transporte, além de baixa escolaridade.

Abordar problemas de saúde como falta de higiene, falta de adesão ao pré-natal, diabetes e hipertensão arterial, de forma descontextualizada pode levar a uma ação profissional alienada e certamente de baixa resolutividade e de pouco impacto no perfil epidemiológico.

Diante de condições adversas e exclusão social, algumas famílias apresentam uma tranqüilidade quase apática, porém consciente dos sonhos que nunca se realizarão. Talvez essa seja a estratégia pela qual as famílias conseguem obter $o$ lar equilibrado emocionalmente.

$\mathrm{Na}$ enfermagem contemporânea, o cuidar humano resgata e discute a ampliação da arte de cuidar, sendo considerada como um valor, um comportamento, uma filosofia, uma arte e uma ciência. Para tanto, há a necessidade de se buscar, na prática do cuidar, a geração de conhecimento (DAHER et al, 2002).

VASCONCELOS (2001), aponta que conhecer a vida familiar é muito mais que ter acesso a informações importantes sobre como os moradores pensam e organizam suas vidas. Para ele, é necessário experimentar o jeito de viver, despido do preconceito e da diferença cultural. Para tal, é necessário que a intimidade familiar nos esteja aberta, o que decorre do afeto. No Programa de Saúde da Família a maioria dos serviços ainda é baseada no modelo do pronto-atendimento, isto é, centrado no atendimento pontual dos problemas, na maioria das vezes sem acompanhamento dos usuários no contexto familiar e comunitário. O eixo que tem orientado a intervenção baseia-se nos programas de saúde pública, planejados e sistematizados hierarquicamente nas instâncias superiores do setor saúde. Estes fatos levam a que, nas visitas domiciliárias, a atenção do profissional geralmente se restringe aos aspectos que os diversos programas priorizam, o que empobrece seu alcance, por não considerar a complexidade das manifestações locais dos problemas de saúde. Trabalhar com famílias em situação de risco deve ser dinâmico, em contínua transformação, porque o percurso pode ser modificado pelos sujeitos acompanhados. O eixo desse trabalho deve ser a educação, como ato transformador, inclusive da própria instituição de saúde, e acrescentamos, das próprias práticas da Estratégia Saúde da Família.

Frente a famílias que apresentam indicadores de situação de risco, cabe aos profissionais de saúde buscar formas de intervenção que diminuam o sofrimento e os riscos de vida presenciados, auxiliar a população na execução do controle social, valorizar e ressaltar os elementos positivos da família, respeitando as diferenças culturais e os limites postos pelas mesmas, respeitando sua forma diferenciada de responder às diversas formas de apresentação dos problemas. Nesse sentido, cabe, principalmente, repensar nossa prática autoritária e normatizadora de relacionarmos com o mundo popular, promovendo o fortalecimento da família (VASCONCELOS, 2001).

\section{CONSIDERAÇÕES FINAIS}

Esta investigação permitiu identificar os fatores de risco do D.E. "Risco para paternidade ou maternidade prejudicada" entre 26 famílias situação de risco social cadastradas no Programa de Saúde da Família, equipe 02, da Região Leste de Goiânia.

Entre os de maior freqüência ( $\geq 250 \%$ ) foram identificados Classe socioeconômica baixa; Dificuldades financeiras; Falta de recursos; Pobreza; Ambiente doméstico pobre; Gravidez não-planejada ou não-desejada; Criança não-desejada ou nãoplanejada; Falta de uma rede social de apoio; Isolamento social; Baixo nível ou desenvolvimento educacional; Falta de acesso a recursos; Falta de transporte; Desemprego; Fracas habilidades para resolução de problemas; e Trabalho de parto e ou partos difíceis.

O conhecimento destes fatores nos aponta necessidades de um planejamento de medidas de apoio à família, numa ação interdisciplinar e interinstitucional.

Talvez pelo nosso despreparo em relação ao enfrentamento dos conflitos afetivos decorrentes da convivência com as famílias em situação de risco, seu sofrimento e miséria, gerou em nós sentimentos de frustração e emoções intensos e perturbadoras.

Fomos aos poucos descobrindo que era possível trabalhar com família de uma forma diferente. Permeando vários horizontes, levantávamos diversas possibilidades de intervenção com a família. Tentávamos nos colocar na posição do outro, e isto nos fazia descobrir novos sentimentos, valores, atitudes e comportamentos, além de muitos questionamentos.

No decorrer do trabalho na Equipe de Saúde da Família, os profissionais que realmente se envolvem com a comunidade, podem em casos de população carente, descobrir um universo à parte, e nesse caso torna-se necessário o estabelecimento de um suporte emocional que se preocupe com a sobrecarga emocional destes trabalhadores da saúde. Caso contrário, poderão ocorrer mecanismos de defesa de 
evitamento e encouraçamento, o que certamente frustrará o ideário da Estratégia de Saúde da Família.

Para direcionar a atuação de enfermagem embasada no modelo de avaliação de famílias, faz-se necessário o aprendizado de novas técnicas de cuidado da saúde, essencialmente, aquelas voltadas para metodologias educativas e de apoio, bases para uma intervenção efetiva junto à estas famílias.

\section{REFERÊNCIAS BIBLIOGRÁFICAS}

ANGELO, M.; BOUSSO, R. S. Fundamentos da Assistência à Família em Saúde. In: BRASIL. Instituto para o Desenvolvimento da Saúde. Manual de Enfermagem. Programa de Saúde da Família. Universidade de São Paulo. Ministério da Saúde. Brasília: Ministério da Saúde. 2001.

CARPENITO, L. J. Planos de Cuidados de Enfermagem e Documentação: diagnósticos de enfermagem e problemas colaborativos. Trad. Ana Maria Vasconcelos Thorell. 2. ed. Porto Alegre: Artes Médicas Sul, 1999.

CARVALHO, I. M. M. de; ALMEIDA, P. H. de. Família e proteção social. São Paulo em Perspectiva, São Paulo, v.17,n.2,p.109-122, 2003.

CARVALHAES, M. A. de B. L.; BENÍCIO, M. H. D’A. Capacidade materna de cuidar e desnutrição infantil. Rev. Saúde Publica, v.36, n.2, p.188-197, 2002.

CIAMPONE, M. H. et al; Representações sociais da equipe de enfermagem sobre a criança desnutrida e sua família. Revista Latino-Americana de Enfermagem, Ribeirão Preto, v.7, n.3, p. 17-24, julho, 1999.

DAHER, D. V.; ESPÍRITO SANTO, F. H. do ; ESCUDEIRO, C. L. Cuidar e pesquisar: práticas complementares ou excludentes? Revista LatinoAmericana de Enfermagem, Ribeirão Preto, v.10,n.2, p.145-150, mar/abril. 2002.

GODINHO, R. A. et al; Adolescentes e grávidas: onde buscam apoio? Revista Latino-Americana de Enfermagem, Ribeirão Preto, v. 8, n. 2, p. 25-32, abril, 2000.

MARTIN, V. B.; ANGELO, M. Significado do conceito saúde na perspectiva de famílias em situação de risco pessoal e social. Revista Latino-Americana de Enfermagem, Ribeirão Preto, v. 6, n. 5, p. 45-51, dezembro, 1998.

NANDA. Diagnósticos de Enfermagem da NANDA: definições e classificação - 2001 - 2002/organizado por North American Nursing Association; trad. Jeanne Liliane Marlene Michel. Porto Alegre: Artmed, 2002.

SILVA, L. de F. et al. Famílias e Redes Sociais: o uso das práticas populares no processo saúde e doença. In: SILVA, Y. S.; FRANCO, M. C. (Org). Saúde e Doença: Uma abordagem cultural da enfermagem. Florianópolis: Papa-Livro, 1996.

SOUZA, R. R. A população em primeiro lugar. Revista Brasileira de Saúde da Família, Brasília: Ministério da Saúde, p.4-11, novembro. 1999.
VASCONCELOS, E. M. Educação popular e a atenção à saúde da família. Eymard Mourão Vasconcelos; com a participação de Eduardo Mourão Vasconcelos [et al.]. 2 ed. São Paulo: Hucitec, Sobral: Uva, 2001.

WRIGHT, L. M.; LEAHEY, M. Enfermeiras e Famílias: um guia para avaliação e intervenção na família. [trad. de Sílvia M. Spada]. 3. ed. São Paulo: Roca, 2002.

Texto recebido em 31/05/2005

Publicação aprovada em 30/08/2005 